\title{
Barometric tides from ECMWF operational analyses
}

\author{
R. D. Ray $^{1}$ and R. M. Ponte ${ }^{2}$ \\ ${ }^{1}$ NASA Goddard Space Flight Center, Greenbelt, Maryland, USA \\ ${ }^{2}$ Atmospheric and Environmental Research, Inc., Lexington, Massachusetts, USA
}

Received: 18 October 2002 - Revised: 23 March 2003 - Accepted: 25 March 2003

\begin{abstract}
The solar diurnal and semidiurnal tidal oscillations in surface pressure are extracted from the operational analysis product of the European Centre for Medium Range Weather Forecasting (ECMWF). For the semidiurnal tide this involves a special temporal interpolation, following Van den Dool et al. (1997). The resulting tides are compared with a "ground truth" tide data set, a compilation of welldetermined tide estimates deduced from many long time series of station barometer measurements. These comparisons show that the ECMWF (analysis) tides are significantly more accurate than the tides deduced from two other widely available reanalysis products. Spectral analysis of ECMWF pressure series shows that the tides consist of sharp central peaks with modulating sidelines at integer multiples of $1 \mathrm{cy}-$ cle/year, superimposed on a broad cusp of stochastic energy. The integrated energy in the cusp dominates that of the sidelines. This complicates the development of a simple empirical model that can characterize the full temporal variability of the tides.
\end{abstract}

Key words. Meteorology and atmospheric dynamics (waves and tides)

\section{Introduction}

The spectrum of atmospheric surface pressure exhibits strong peaks at diurnal and semidiurnal periods, a well-known manifestation of the solar atmospheric tides. These global atmospheric oscillations, forced primarily by water-vapor and ozone radiational absorption, constitute a major part of the total surface pressure variance in the tropics and make an important contribution to the local daily cycle elsewhere. The tides have long been studied both in their own right (Chapman and Lindzen, 1970) and for what they potentially reveal about the atmosphere (e.g. Wilkes, 1949; Cooper, 1982; Hamilton, 1983; Braswell and Lindzen, 1998). Our work is partly motivated by modern oceanographic and geodetic ap-

Correspondence to: R. D. Ray (richard.ray@gsfc.nasa.gov) plications: tidal pressure waves load the ocean and land, and the resulting deformations must be precisely modeled when analyzing, for example, sea level (Ponte and Gaspar, 1999) or gravity (Wahr et al., 1998; Velicogna et al., 2001). For these and other applications, globally well-resolved barometric tides $\mathrm{S}_{1}(p)$ and $\mathrm{S}_{2}(p)$ are required.

Global $\mathrm{S}_{1}(p)$ and $\mathrm{S}_{2}(p)$ fields have traditionally been constructed by empirical means (e.g. Haurwitz and Cowley, 1973; Dai and Wang, 1999; Ray, 2001). Tidal harmonic analyses of hourly barometric measurements, taken at a large number of globally distributed stations, can be spatially interpolated (optimally or otherwise) to yield globally gridded fields. More recently, estimates based on general circulation models (Zwiers and Hamilton, 1986; Madden et al., 1998) and on analyses produced by weather centers (Hsu and Hoskins, 1989; Van den Dool et al., 1997; Ray, 2001) have also been examined. The latter products are of special interest because they are based on "optimal" estimates of the state of the atmosphere arrived at through advanced modeling and data assimilation techniques. Gridded analysis fields have a typical 6-hour sampling interval, however, which leads to $S_{2}$ solutions that are standing waves, rather than westward propagating, and with much underestimated amplitudes near longitudes where sampling times happen to coincide with times of the $S_{2}$ nodes. Temporal interpolation methods can be used to recover the fully propagating $S_{2}$ tide (Van den Dool et al., 1997), but their general usefulness remains to be tested.

Comparisons of global barometric tides, derived from the available gridded analyses with the meteorological station data provide a useful test of the analyzed fields and also the interpolation methods (Van den Dool et al., 1997). Ray (2001) examined $S_{2}(p)$ in the reanalyses of the National Centers for Environmental Prediction-National Center for Atmospheric Research (NCEP-NCAR), as interpolated by Van den Dool et al. (1997), and the NASA Goddard Earth Observing System (GEOS-1), for which 3-h fields were available and no interpolation was required. Comparisons with data revealed significant inadequacies in the representa- 
tion of $\mathrm{S}_{2}(p)$ in both reanalyses (Ray, 2001). Similar detailed comparisons for $\mathrm{S}_{1}(p)$ are missing, but significant discrepancies between theoretical and observed estimates have been noted (Braswell and Lindzen, 1998; Ray, 1998).

In this paper, we examine $\mathrm{S}_{1}(p)$ and $\mathrm{S}_{2}(p)$ solutions based on the operational analyses of the European Centre for Medium-Range Weather Forecasts (ECMWF) (Hsu and Hoskins, 1989). We find that these solutions are far more accurate than those from the two reanalysis fields considered by Ray (2001).

In what follows, we first describe the ECMWF fields and the methodology used to create climatological daily cycles of surface pressure (Sect. 2), and then discuss in detail respective $\mathrm{S}_{2}(p)$ and $\mathrm{S}_{1}(p)$ solutions in comparison with those from other analyses (Ray, 2001) and the barometer data (Sects. 3 and 4). An important aspect of the atmospheric tides is their variability (Chapman and Lindzen, 1970; Lindzen, 1990), and both spectral analysis and monthly climatologies are used to assess these effects in the ECMWF fields (Sect. 5).

\section{Daily cycle in ECMWF surface pressure fields}

\subsection{Six-hourly climatologies}

Surface pressure $\left(p_{a}\right)$ analyses from ECMWF were obtained from the archives at NCAR for the period 1986-1998. Prior to 1986 ECMWF analyses were provided on coarser grids, and at the start of our study 1998 was the last complete year in the NCAR archives. For the 13-year period considered, surface pressure fields were available four times daily (00:00, 06:00, 12:00, and 18:00 UT) on a regular $1.125^{\circ}$ grid in longitude and Gaussian grid in latitude with 160 points. Values were interpolated in latitude to a regular $1.125^{\circ}$ grid to facilitate analyses. For the purposes of studying seasonal modulations of the barometric tides, we calculated monthly climatologies of the daily cycle in $p_{a}$. For each month all the analyses at each given time of day (totaling the number of days in respective month times 13 years) were averaged to obtain four mean fields at 00:00, 06:00, 12:00, and 18:00 UT. Results in the paper are based on these monthly climatologies, with the daily time mean at each grid point removed.

Figure 1 shows the 13-year averaged daily cycle in $p_{a}$ obtained by averaging the 12 monthly climatologies. A clear zonal wave number-two pattern, approximately alternating in sign every 6 hours, underlines the dominant presence of the $S_{2}$ tide, but its westward propagation cannot be discerned from the 6-h maps. The differences in patterns separated by $12 \mathrm{~h}$ also hint at the presence of variability associated with the $\mathrm{S}_{1}$ tide. Amplitudes are largest in the tropics and decay to small values at high latitudes. Spatial variations are smooth over the oceans but shorter scale structures appear over land and particularly so over high orography. In general, the overall characteristics of the ECMWF daily cycle in $p_{a}$ are consistent with past theoretical and observational studies of the air tides (Lindzen, 1990; Dai and Wang, 1999).
ECMWF results are also broadly similar to the climatologies based on the NCEP-NCAR reanalysis (Van den Dool et al., 1997), although ECMWF peak amplitudes are consistently smaller by $\sim 0.5 \mathrm{mb}$ in the tropics.

As a preliminary assessment of seasonal effects, Figs. 2 and 3 show $p_{a}$ maps for March and June climatologies, respectively. At low latitudes amplitudes are larger in March than in June by $\sim 0.5 \mathrm{mb}$, indicating a substantial semiannual modulation of the wave number-two pattern associated with $\mathrm{S}_{2}$. Stronger amplitudes in March coincide with the maximum solar insolation (and thus strongest forcing) over tropical regions. Peak amplitudes do not particularly follow the shift in maximum solar insolation from the equator in March to the Tropic of Cancer $\left(23^{\circ} \mathrm{N}\right)$ in June, which is not unexpected since the atmosphere's response to radiational forcing is dominated by equatorially symmetric modes (Lindzen, 1990). Comparisons between June and December climatologies (not shown), nevertheless, indicate that the response over land and land-ocean contrasts are enhanced in the summer hemisphere. Substantial annual modulation of $S_{1}$ signals over land are, therefore, expected. More detailed discussion of seasonal effects is given below when examining $S_{1}$ and $\mathrm{S}_{2}$ solutions.

\subsection{Time interpolated climatologies}

As previously discussed, the 6-h fields in Fig. 1 cannot represent the propagating $S_{2}$ signals. For proper resolution of the $S_{2}$ tide, we followed essentially the interpolating method developed by Van den Dool et al. (1997), which implicitly assumes that the barometric tide propagates westward with the Sun at approximately $15^{\circ} / \mathrm{h}$. Merely shifting one pattern by $90^{\circ}$ westward in Fig. 1 does not yield the observed pattern 6 hours later, however, partly because of the presence of nonmigrating tidal signals. Nonmigrating components associated with land features and having relatively short spatial scales have been noted (Fig.1). To minimize the effects of such signals on the interpolation, at each latitude filtering was applied to the climatological fields to retain only the zonal mean plus the first 10 zonal wave numbers, as in Van den Dool et al. (1997). The $S_{2}$ solutions described below were not overly sensitive to the filter wave number cutoff and results with more smoothing did not lead to any measurable improvements.

Given the longitudinal grid spacing of $1.125^{\circ}$, we chose to create an interpolated series at 45-min intervals, which gave an integral number of grid points (10) for the distance traveled by the tides between samples. The interpolation procedure was as in Van den Dool et al. (1997) with one difference: the filtered $p_{a}$ patterns were assumed to propagate at the nominal rate of $15^{\circ}$ /hour without any differential phase adjustments for the various zonal wave numbers. Van den Dool et al. noted that the phase propagation of each wave number can deviate from the expected values and tried to allow for such dispersion effects. The determination of the phase propagation was, however, ambiguous. For simplicity, we have ignored these effects in our procedure. 

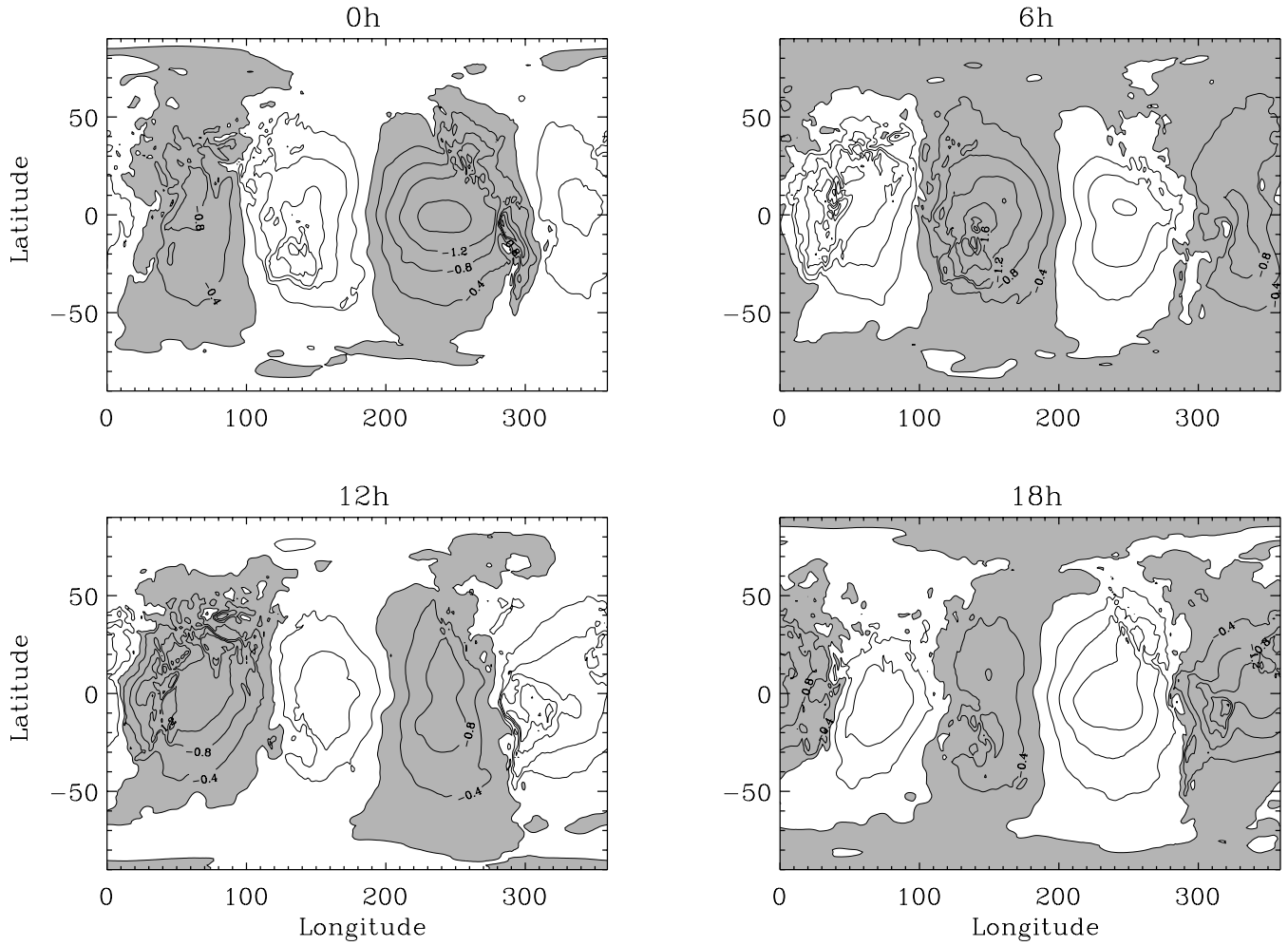

Fig. 1. Climatological daily cycle of surface pressure (mbar) calculated from 13 years of ECMWF analyses at 00:00, 06:00, 12:00, and 18:00 UT. Negative values are shaded. Contour interval is $0.4 \mathrm{mb}$.
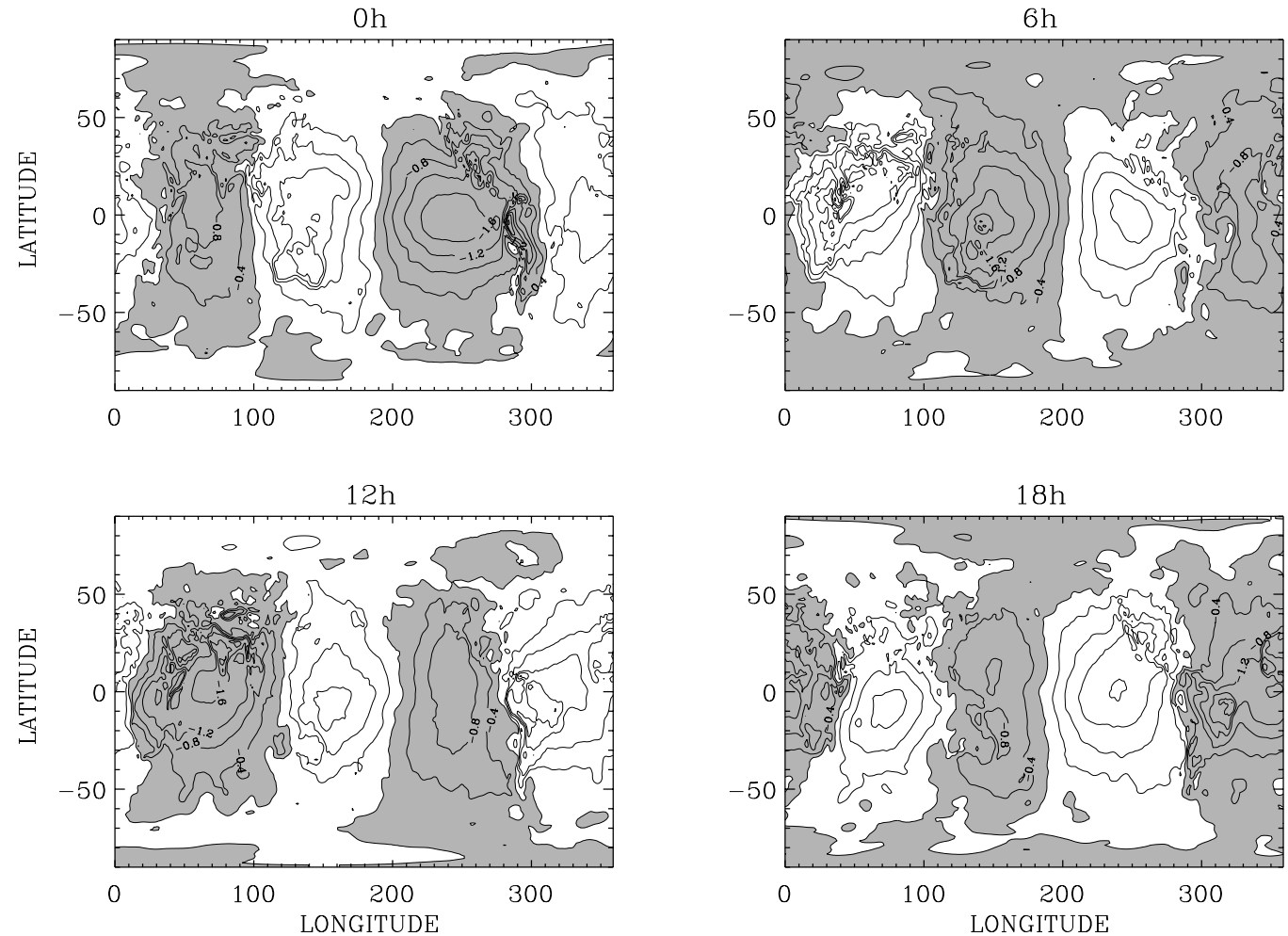

Fig. 2. As in Fig. 1 but showing climatological daily cycle for March. 

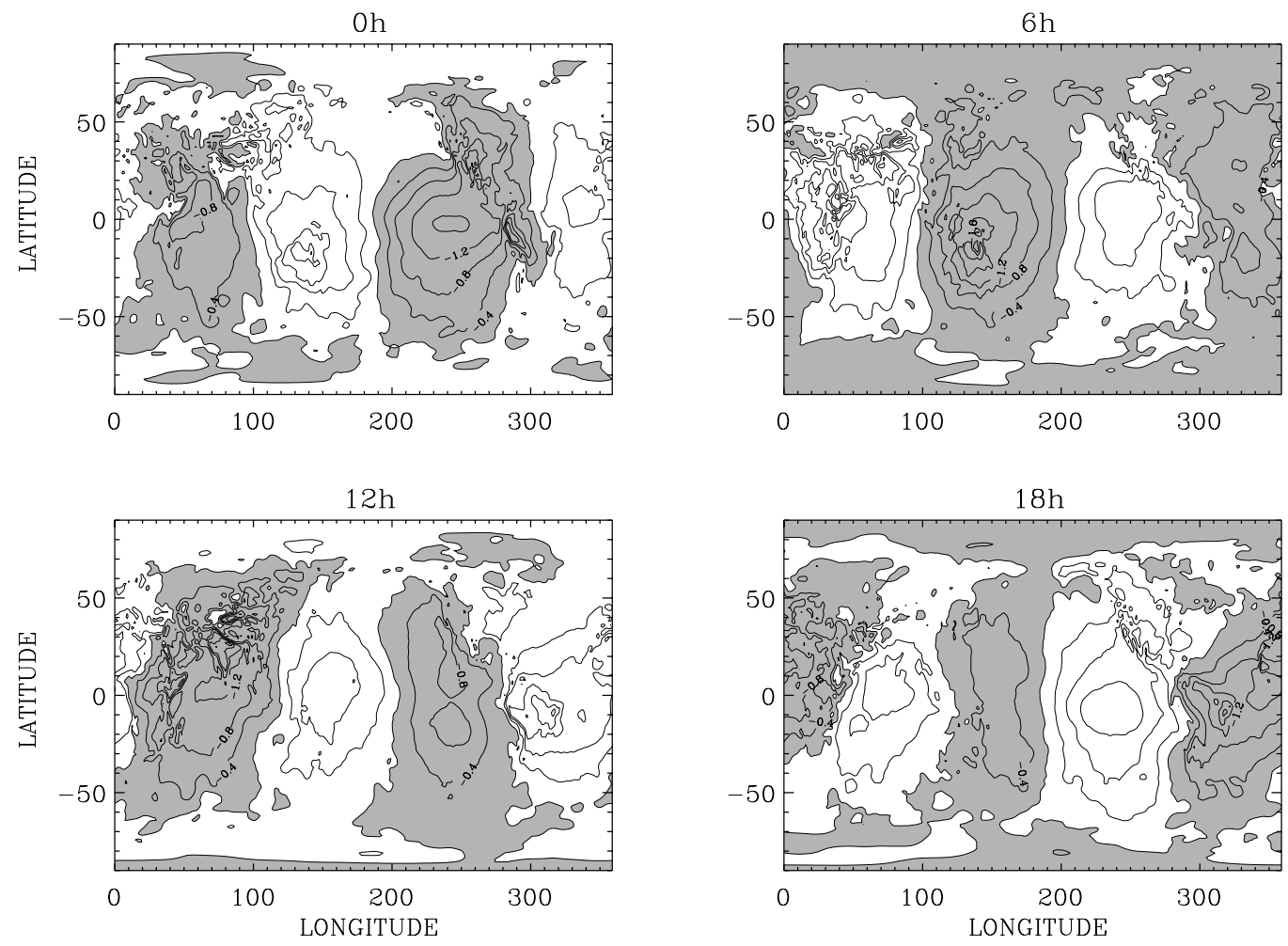

Fig. 3. As in Fig. 1 but showing climatological daily cycle for June.

To create interpolated values at any time $t_{a}+\delta t$ in hours, where $t_{a}$ is a time for which an analysis is available, the following procedure was applied: (1) the climatological pattern at $t_{a}$ was propagated westward by a distance of $15^{\circ} \times \delta t$ to yield $W$; (2) the next available climatological pattern at $t_{a}+6$ was propagated eastward by a distance of $15^{\circ} \times(6-\delta t)$ to yield $E$; (3) the two resulting fields were averaged as $[(6-\delta t) \times W+\delta t \times E] / 6$. Interpolated solutions are thus exactly equal to the observed (filtered) climatologies at 00:00, 06:00, 12:00, and 18:00 and correspond to a weighted average of the two closest patterns at other times, with propagation effects accounted for by the shifting in (1) and (2). Figure 4 shows, as an example, the resulting 13-year average daily cycle in $p_{a}$ at $1.5 \mathrm{~h}$ intervals. The $p_{a}$ patterns exhibit little contamination by short scale land effects and progress smoothly westward in time, as intended.

\section{Annual mean $S_{2}$ tide}

Global charts of the amplitude and phase of the $S_{2}$ tide can be readily extracted from the interpolated fields of Fig. 4 by a least-squares fit to a simple sinusoid at every geographic location:

$\mathrm{S}_{2}(p)=A_{2} \cos \left(2 T-\varphi_{2}\right)$.

The results are shown in Fig. 5. With $T$ taken as Universal Time (in appropriate units), the phase $\varphi$ is a "Greenwich phase lag" as traditionally employed in ocean-tide studies.
By tracing out successive contours of $\varphi$, the high-pressure peak of $S_{2}(p)$ can be easily followed in time. Figure 5 shows it marching westward, leading the Sun by roughly $60^{\circ}$, or about $2 \mathrm{~h}$, a well-known feature of $\mathrm{S}_{2}$.

Similar figures have been computed from other reanalysis surface pressure fields (e.g. Dai and Wang, 1999; Ray, 2001) and from simulations (e.g. Zwiers and Hamilton, 1986). The annual mean $\mathrm{S}_{2}$ tide, derived from the NASA Goddard Earth Observing System (GEOS-1) reanalysis (Schubert et al., 1993) and from the NCEP-NCAR reanalysis (Kalnay et al., 1996), temporally interpolated by Van den Dool et al. (1997), was extensively compared by Ray (2001). Comparison of Fig. 5 with corresponding NCEP-NCAR and GEOS- 1 charts (Figs. 2 and 3 of Ray, 2001) shows gross similarities but also shows some immediate differences. The ECMWF tidal amplitudes are smaller in the tropical latitudes than NCEP and more zonally symmetric than GEOS-1. The NCEP reanalysis amplitudes are thought to be too large (Van den Dool et al., 1997).

More quantitative comparisons and tests of these $S_{2}$ fields can be obtained by employing the set of "ground truth" $\mathrm{S}_{2}$ estimates of Ray (2001). These are tide estimates based on analyses of long time series of barometric pressure measurements from 428 widely distributed meteorological stations. This set of station estimates is a merger of three previous compilations by Haurwitz (1956), Hamilton (1980), and Ray (1998). Considerable care was taken in deriving each of the tidal estimates, and they likely represent the best "ground truth" knowledge we have of the $S_{2}$ tide. While temporal 

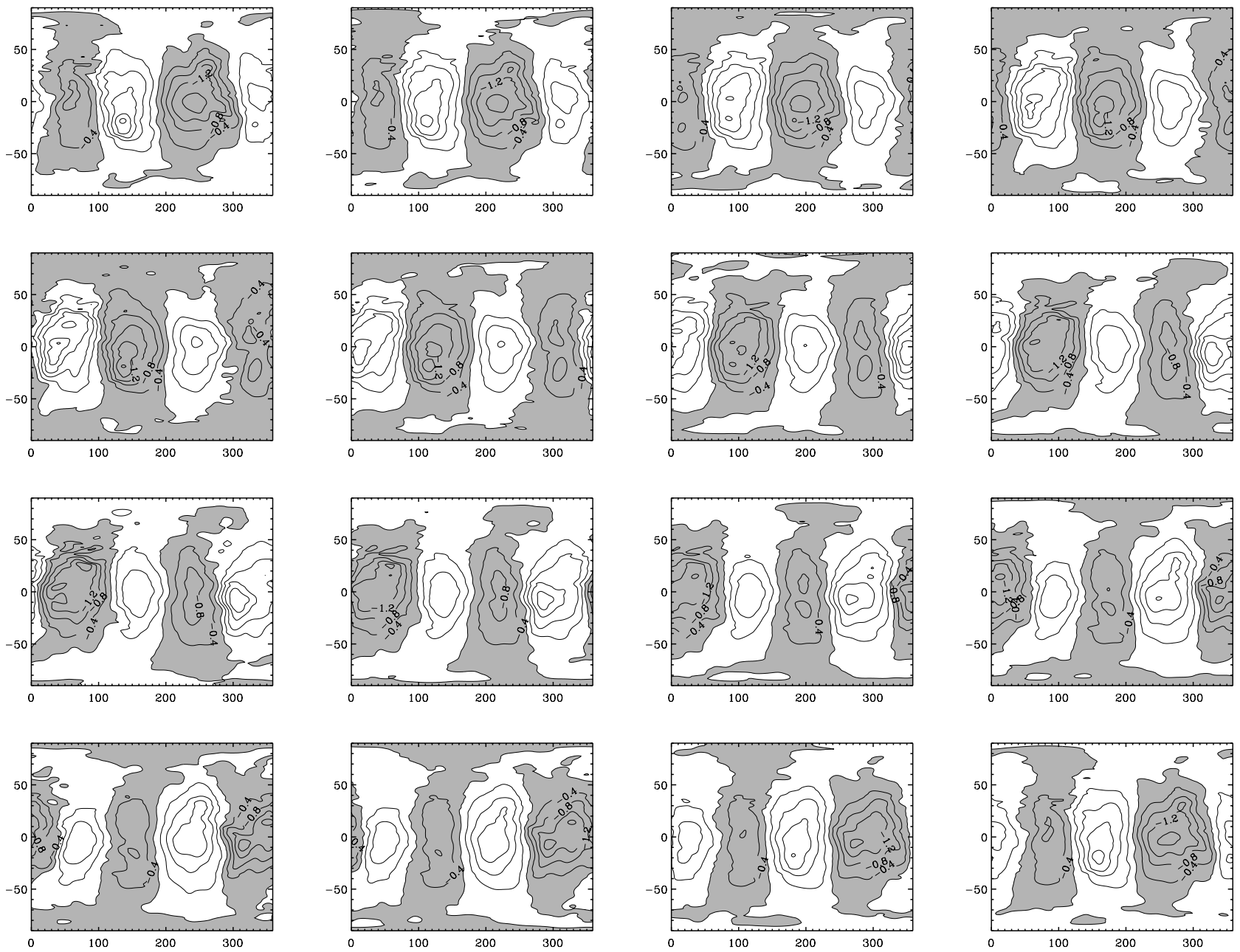

Fig. 4. Interpolated climatological daily cycle at $1.5 \mathrm{~h}$ intervals. Time marches horizontally from the top left corner (00:00 UT) to the bottom right corner (22:30 UT).

Table 1. $\mathrm{S}_{2}$ rms differences $(\mu \mathrm{b})$ with station estimates

\begin{tabular}{llccccc}
\hline & & $\begin{array}{c}\text { all } \\
\text { stations }\end{array}$ & $\begin{array}{c}\text { above } \\
1000 \mathrm{~m}\end{array}$ & $\begin{array}{c}\text { latitude } \\
\leq 30^{\circ}\end{array}$ & $\begin{array}{c}\text { ocean } \\
\text { stations }\end{array}$ & MAD* \\
\hline NCEP-NCAR & reanalysis & 151 & 245 & 296 & 208 & 82 \\
GEOS-1 & reanalysis & 168 & 196 & 300 & 238 & 85 \\
ECMWF $\dagger$ & operational & 124 & 177 & 243 & 211 & 69 \\
ECMWF & operational & 112 & 159 & 230 & 134 & 52 \\
ECMWF(2) & operational & 110 & 141 & 221 & 156 & 54 \\
\hline
\end{tabular}

\footnotetext{
* Median Absolute Difference

$\dagger$ Before phase correction
}

Of 428 stations, 42 are above $1000 \mathrm{~m}, 157$ are low latitude, 46 are classified oceanic.

Solution ECMWF(2) corresponds to Fig. 7.

variability in the tide (see below) can itself produce differences between models and stations, this has been minimized by using, to the greatest extent possible, stations with an integral number of full calendar years (thereby minimizing intra-annual variations) and long multi-year time series (min- imizing interannual variations). Table 1 summarizes the rootmean-square (rms) and median absolute differences (MAD) between the 428 stations and each of the three gridded products we have at our disposal. In all cases our temporally interpolated ECMWF fields appear to yield the more accurate 

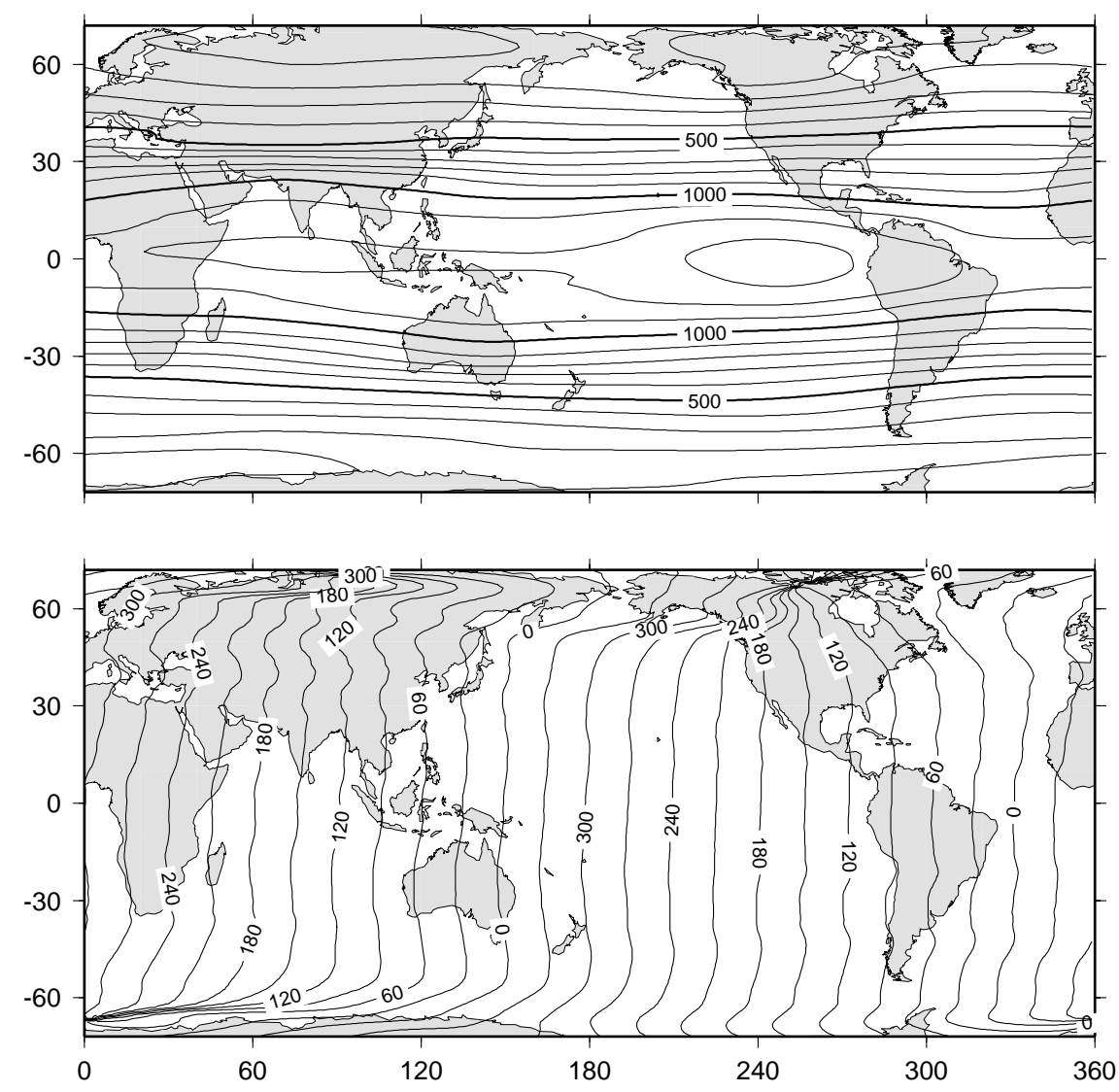

Fig. 5. Amplitude $(\mu \mathrm{b})$ and Greenwich phase lags (degrees) of the $\mathrm{S}_{2}(p)$ tide, calculated as described in the text. The phase contour interval of $30^{\circ}$ corresponds to $1 \mathrm{~h}$ in time.

estimates of $\mathrm{S}_{2}$.

We should stress that Table 1 compares ECMWF operational analysis tides with GEOS and NCEP-NCAR reanalysis tides. The difference between meteorological centers is probably less significant than the differences between a reanalysis and a modern analysis, the latter having considerably finer resolution in both vertical and horizontal (e.g. T170 vs. T62 grids). In fact, an unpublished study of NCEP operational analysis fields suggests that its tidal signals are more realistic than the NCEP reanalysis (H. Van den Dool, personal communication, 2002).

Figure 6 shows the amplitude and phase differences between the ECMWF tide and each of the 428 station estimates, plotted as a function of latitude. Amplitude differences are noticeably larger and more scattered in tropical latitudes where the tide itself is maximum. At first glance, and consistent with Table 1, this scatter is less pronounced than in similar diagrams for NCEP and GEOS-1 (Ray, 2001, Figs. 5 and 6). Also noticeable in Fig. 6 (top) is a consistent phase discrepancy between ECMWF and the test stations. Except for a small band near the equator, all latitudes between $60^{\circ} \mathrm{N}$ and $60^{\circ} \mathrm{S}$ suggest that the ECMWF phases $\varphi$ are too large. (Larger phase scatter in high latitudes is of no significance because of the very small amplitudes.) The mean phase discrepancy in Fig. 6 is $9.7^{\circ}$; the median is $10.4^{\circ}$. A phase error of $10^{\circ}$ implies that the ECMWF $\mathrm{S}_{2}$ tide is generally too late by $20 \mathrm{~min}$. Similar phase discrepancies were noticed in the other two reanalysis tides (Ray, 2001), with NCEP too late by roughly $30 \mathrm{~min}$ and GEOS- 1 too early by roughly $60 \mathrm{~min}$ (depending on how the time-tag in the GEOS product is interpreted). We are not in a position to offer credible explanations for the cause of such time discrepancies, except to say that they appear to be fairly robust (as in Fig. 6) and that the errors cannot be in the station data. The statistics of Table 1 show the model-station comparisons both before and after the model phases have been corrected, and the statistics for the corrected phases are lower, as expected. (Both NCEP and GEOS-1 statistics reflect phases already corrected for their deduced systematic errors, as discussed more fully in Ray, 2001.)

A possibly legitimate criticism of Fig. 5 is that the map may be too zonally symmetric, an artifical by-product of the wave number filtering employed by us and by Van den Dool et al. (1997). In fact, examination of the Fig. 1 mean pressures suggests that $S_{2}$ may well embody significant nonmigrating components - note, for example, the outline of Australia, evident in several of the diagrams of Fig. 1. Such land-fixed features are evident in the GEOS- 1 semidiurnal tide, which was deduced directly from the 3-h pressure data without wave number filtering (Dai and Wang, 1999; Ray, 

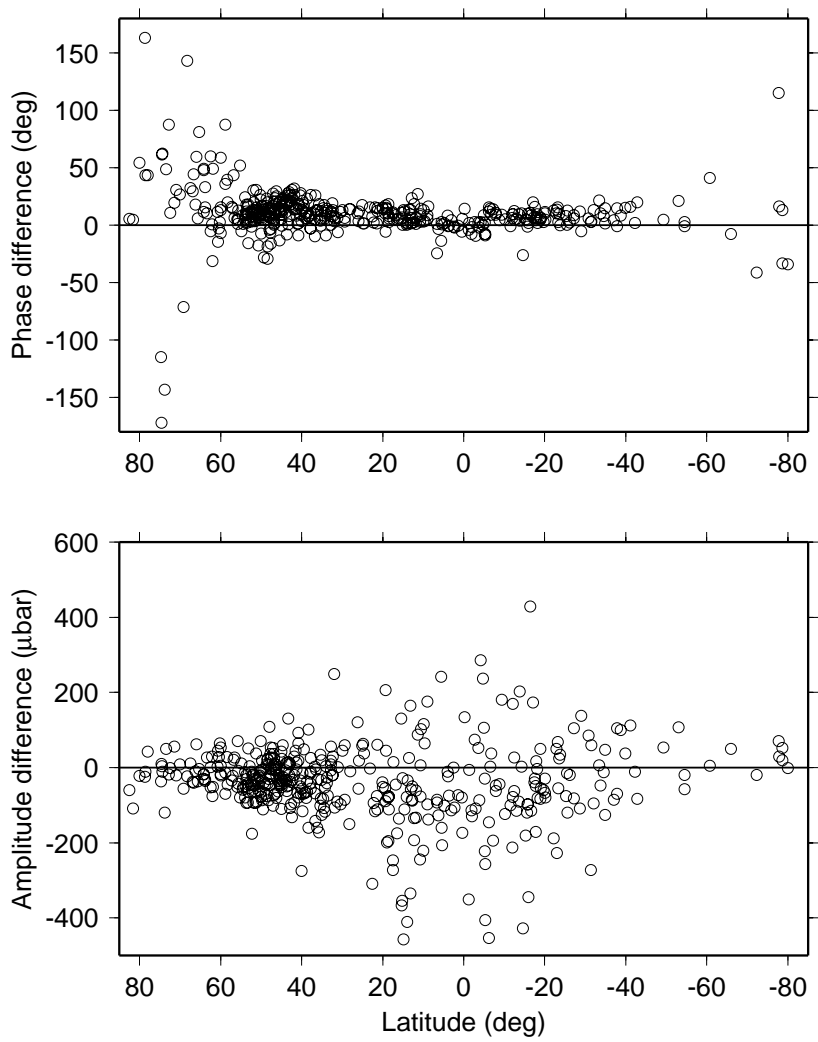

Fig. 6. Amplitude and phase differences between ECMWF-implied $\mathrm{S}_{2}(p)$ tide and estimates based on 428 barometer stations. A small systematic error in the phases is readily apparent.

2001), and which may thus be more realistic in this regard than our Fig. 5. Yet the few features that can be tested by the ground-truth stations suggest that the non-migrating GEOS1 features must be treated with caution. For example, while the amplitude contours in Fig. 5 are almost perfectly eastwest across the North Atlantic Ocean, the GEOS-1 amplitudes collapse to a minimum at mid-ocean (Dai and Wang, 1999, Fig. 16); the ground-truth stations, however, suggest no such collapse (Ray, 2001).

Given the 6-h ECMWF sampling, it is impossible to recover unambiguously any real non-migrating component of $\mathrm{S}_{2}$. We can, however, restore the non-migrating in-phase component $A_{2} \cos \varphi_{2}$ by fitting a sinusoidal wave to the difference between our model Eq. (1) and the data of Fig. 1. The modified $S_{2}$ amplitude and phase charts are shown in Fig. 7, and the relevant ground-truth statistics are listed in Table 1 under the label "ECMWF(2)." According to Table 1 the land regions of the new solution, and especially the high-altitude regions, are more accurate, but the oceanic regions are degraded, and the overall accuracy is about the same.

\section{Annual mean $S_{1}$ tide}

Similar charts may be derived for the diurnal $S_{1}(p)$ tide. In this case, however, it is important to minimize any wave
Table 2. $\mathrm{S}_{1}$ differences $(\mu \mathrm{b})$ with 25 ocean stations

\begin{tabular}{llcc}
\hline & & RMS & MAD* \\
\hline NCEP-NCAR & reanalysis & 112 & 81 \\
GEOS-1 & reanalysis & 124 & 73 \\
ECMWF $\dagger$ & operational & 74 & 51 \\
ECMWF & operational & 66 & 51 \\
\hline
\end{tabular}

* Median Absolute Difference

$\dagger$ Before phase correction

number filtering because it is well known (Haurwitz and Cowley, 1973) that $S_{1}$ is dominated by large non-migrating components with complicated spatial distributions. The $\mathrm{S}_{1}$ tide is evidently susceptable to significant diurnal boundarylayer effects over land masses and land-ocean boundaries. Therefore, we avoid altogether using our temporally interpolated fields to deduce $S_{1}$ and return to the original 6-h fields of Fig. 1, which are sufficient to determine a diurnal wave.

At each geographical location we fit to the four mean pressure fields (i.e. unfiltered fields at 00:00, 0600, 12:00, and 18:00 UT as given in Fig. 1) a sinusoid of form

$\mathrm{S}_{1}(p)=A_{1} \cos \left(T-\varphi_{1}\right)$.

(Oceanographers usually add $180^{\circ}$ to this argument.) The resulting amplitudes $A_{1}$ and phase lags $\varphi_{1}$ are shown in Fig. 8 . The spatial complexity of these fields is highly pronounced relative to the simple semidiurnal wave of Fig. 5. Large non-migrating amplitudes, fixed to certain land features, are clearly apparent. The main migrating component is most apparent over the tropical oceans where the phases again show an approximately constant westward march, now lagging the Sun by roughly $250^{\circ}$, or $17 \mathrm{~h}$ (or, equivalently, leading the Sun by roughly 7 h). From Fig. 8 this migrating (zonal wave number-one) component is no more than perhaps half the size of the semidiurnal wave, while the non-migrating components in some regions (e.g. South America) exceed all semidiurnal amplitudes.

It would be highly desirable to compare the $S_{1}$ tide of Fig. 8 and other reanalysis tides against a "ground truth" data set similar to that used above for $\mathrm{S}_{2}$. Unfortunately, we know of no similar compilation that is reliable. Our efforts to locate Bernard Haurwitz's old compilation have so far proven futile. As a makeshift, but limited, test data set we adopt a set of 25 $\mathrm{S}_{1}$ station estimates from small oceanic islands (Ray, 1998). This set of oceanic stations is, of course, completely inadequate for testing tidal fields over the continents where the $S_{1}$ signal is largest, but it is nonetheless valuable in two ways: as a test of the predominantly migrating $S_{1}$ component, which appears to be best isolated in oceanic stations, and as a reliability test of the oceanic diurnal pressure forcing for those investigators interested in sea level. Comparisons against this 25 -station set of $S_{1}$ estimates are given in Table 2. The required NCEP and GEOS-1 $S_{1}$ fields were deduced in similar 

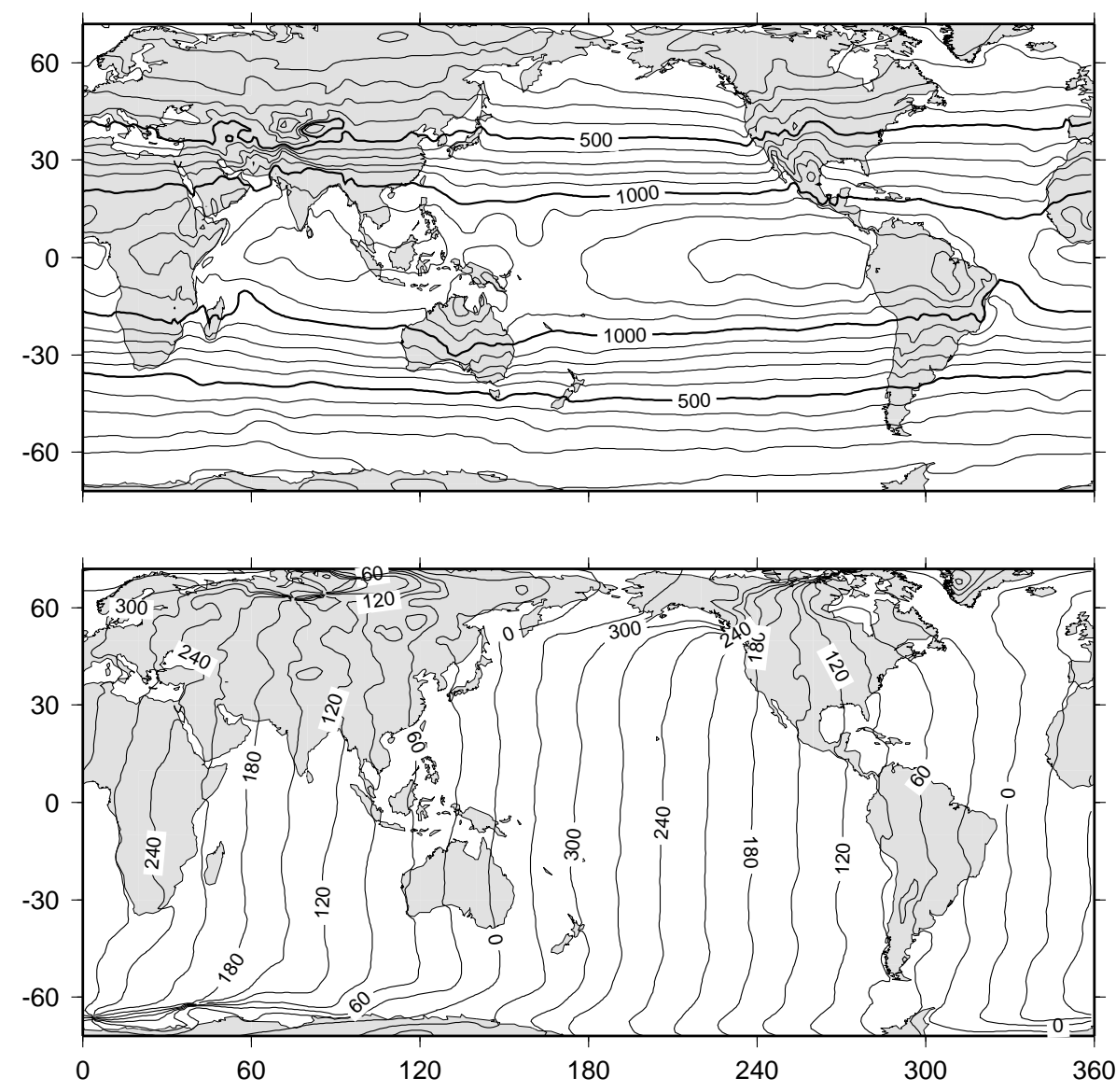

Fig. 7. Amplitude ( $\mu$ b) and Greenwich phase lags (degrees) of the $S_{2}(p)$ tide, as in Fig. 5, except with the in-phase, non-migrating component restored. This solution is denoted "ECMWF(2)" in Table 1.

fashion to the $S_{2}$ fields described above, with the NCEP results based on non-interpolated 6-hour grids.

Our 25-station test set is too limited to allow for a reliable independent estimate of any systematic phase error, as seen above for $\mathrm{S}_{2}$. If the error is caused by a simple time-tag problem (perhaps related to the times that data are ingested into the analysis), then the observed $S_{2}$ error of $10^{\circ}$ implies a $5^{\circ}$ error in $S_{1}$. Applying a $5^{\circ}$ shift to the $S_{1}$ phases does reduce the rms difference with the 25 -station estimates (although the median absolute difference is unchanged). This rms reduction is thus consistent with a 20-min error in the ECMWF pressures.

Table 2 also lists the rms and median absolute differences between the 25 stations and the NCEP and GEOS-1 (reanalysis) diurnal tides. As the statistics make clear, the ECMWF (analysis) $\mathrm{S}_{1}$ estimates are the most reliable of the three products. We emphasize that this statement applies exclusively to the oceanic regions, since none of the 25 stations is from a continental region.

\section{Variability of ECMWF tides}

Significant variability in atmospheric tides is a well-known fact (e.g. Chapman and Lindzen, 1970; Haurwitz and Cowley, 1973). In this section we examine the nature of this variability as implied by the ECMWF series.

\subsection{Monthly analyses}

A standard approach to studying variability in atmospheric tides is to concentrate on seasonal variations, either in terms of monthly means or in terms of the so-called Lloyd seasons (winter, summer, equinoctial); see, for example, Chapman and Lindzen (1970). It is straightforward to form monthly estimates of $\mathrm{S}_{1}(p)$ and $\mathrm{S}_{2}(p)$ from the monthly climatologies discussed in Sect. 2. Figures 9 and 10 show the resulting amplitudes of both tides.

The annual and semiannual modulations in $S_{2}$ are very clear in Fig. 9. In low latitudes the smallest amplitudes occur during June and July, but the largest occur during the two equinoctial seasons of March-April and September-October. This is, of course, consistent with some of the features discussed in the context of Figs. 2 and 3 above. The same pattern of reduced tropical amplitudes in June and July and 

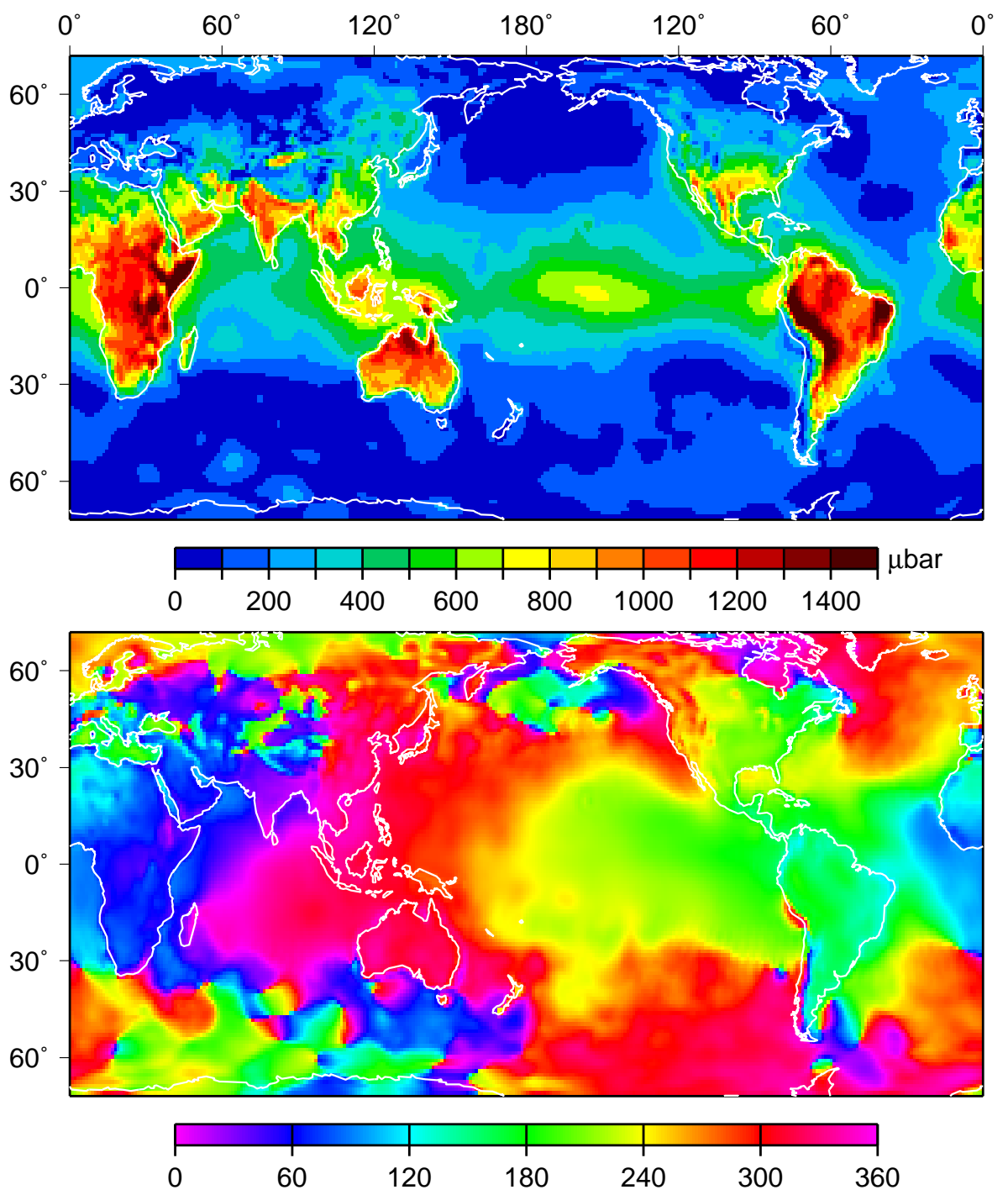

Fig. 8. Amplitude and Greenwich phase lags of the $\mathrm{S}_{1}(p)$ tide, as deduced from ECMWF surface pressures.

strongest amplitudes during equinoctial months appears to hold also for $\mathrm{S}_{1}$, although this is less obvious because of the exceedingly complex spatial patterns.

Figures 11 and 12 summarize the tropical responses by depicting the in-phase and out-of-phase tidal components averaged over all tropical regions of the globe. (Such diagrams are essentially equivalent to Chapman's "harmonic dials".) To allow for proper zonal averaging of these figures, we have converted all phase lags to correspond to mean local solar time: $\kappa_{n}=\varphi_{n}+n \lambda$, where $\lambda$ is east longitude and $n$ is 1 for diurnal and 2 for semidiurnal. (Phases have also been adjusted for the systematic error noted in Fig. 6.) Figure 11 shows an unsymmetrical three-leaf clover pattern for $\mathrm{S}_{2}$, which is consistent with dominant annual and semiannual modulations. Again, the smallest amplitudes are clearly in the northern summer months, while northern winter amplitudes are near the annual mean. Figure 12 separates the tropics into oceanic and land regions because of their dissimilar responses, which is primarily in the large quadrature
$A_{1} \sin \kappa_{1}$ component (i.e. the component corresponding to 06:00 local time). Smallest amplitudes are again in June and July, but otherwise the oceanic regions are dominated by the annual modulation, whereas the land regions have a strong semiannual modulation with relatively weak amplitudes in January and December.

In passing we might mention that Figs. 11 and 12 show both the strengths and the weaknesses of the Lloyd system of averaging. While the "J season" of May-August gives fairly consistent estimates for all three diagrams, the "D season" of November-February includes a very wide range of phases, if not of amplitudes. Averaging such data into one "season" is of doubtful utility.

\subsection{Spectral analysis}

A complementary approach to understanding variability in tides is afforded by spectral analysis of the original surface pressure time series. This approach highlights some of the 

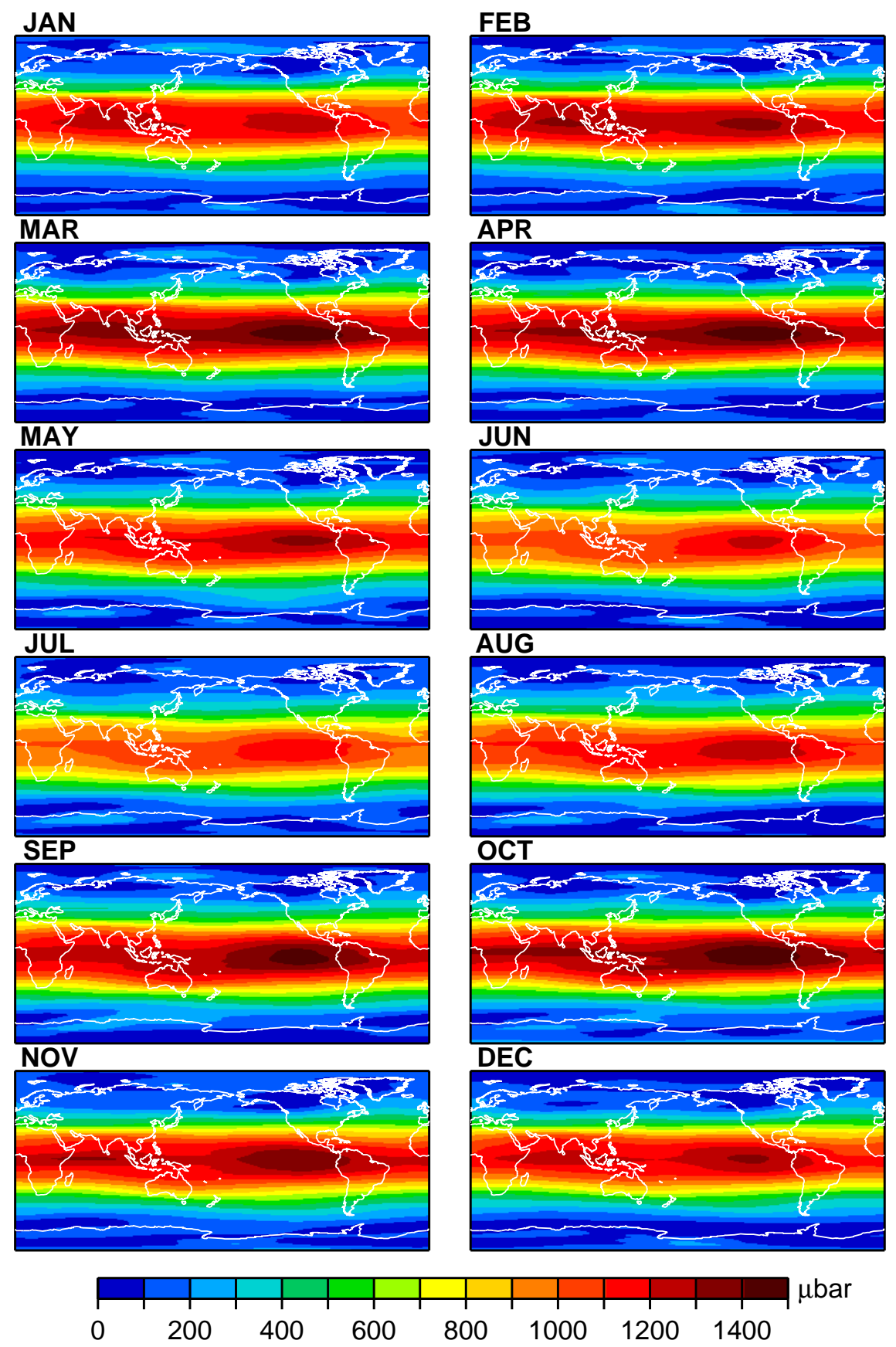

Fig. 9. Monthly mean amplitude of the $S_{2}(p)$ tide as deduced from ECMWF surface pressures.

limitations of using simple monthly means. Wunsch and Stammer (1997) computed the frequency-wave number spectrum of the ECMWF surface pressures, and we here follow up on their work by studying in more detail the spectral structure near the tidal peaks. Wunsch and Stammer display the two-dimensional spectrum, which we need not reproduce here. The two-dimensional spectrum may be summed over all wave numbers to yield a simple one-dimensional frequency spectrum representative of the global pressure field (for details, although in an oceanographic context, see Wunsch and Stammer, 1995).
Figure 13 shows the frequency spectrum estimated from four full years of six-hourly ECMWF surface pressures (years 1996-1999). Although no spectral smoothing has been performed, the spectrum is still relatively smooth because summation over all wave numbers significantly reduces random noise, thus allowing the delineation of some very subtle spectral features. There are clear peaks at the annual $(0.0027 \mathrm{cpd})$ and semi annual $(0.0055 \mathrm{cpd})$ frequencies and at the $S_{1}$ and $S_{2}$ tidal frequencies, the latter occurring at the ECMWF Nyquist frequency. (Compare the somewhat similar Fig. 9 of Ponte, 1993.) There are also some curious 
JAN

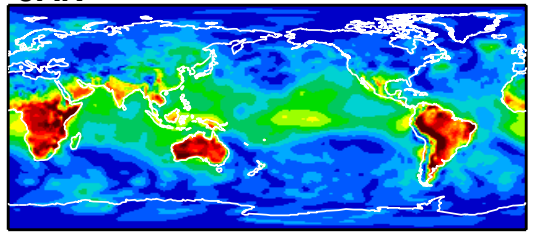

MAR

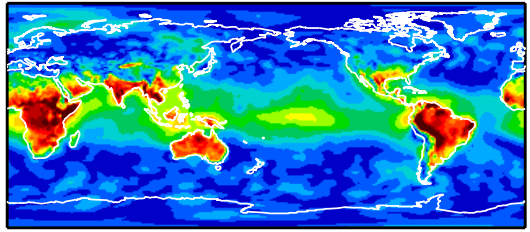

MAY

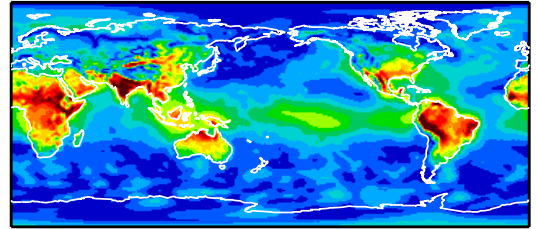

JUL

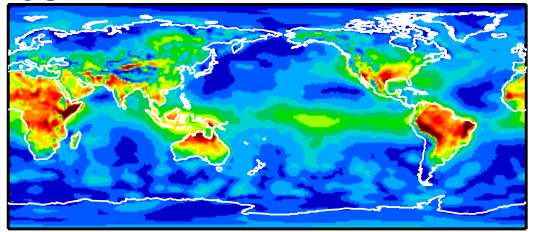

SEP

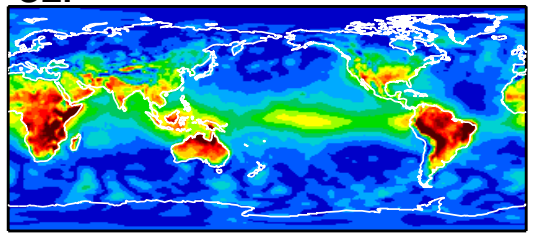

NOV

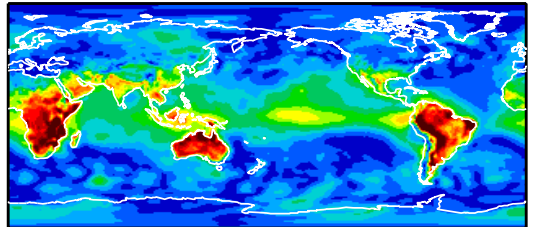

FEB

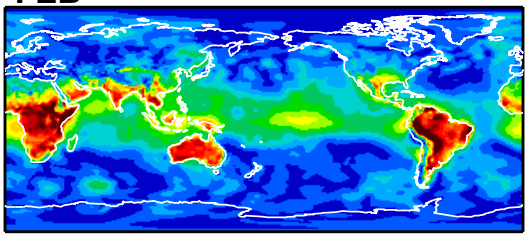

APR

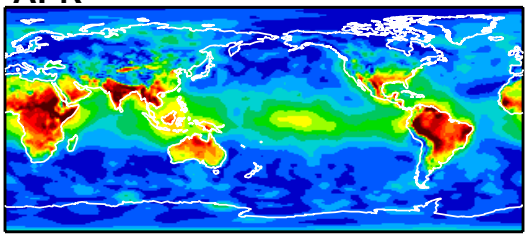

JUN

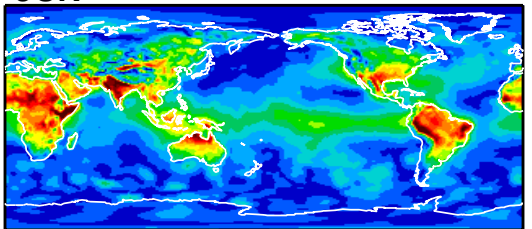

AUG

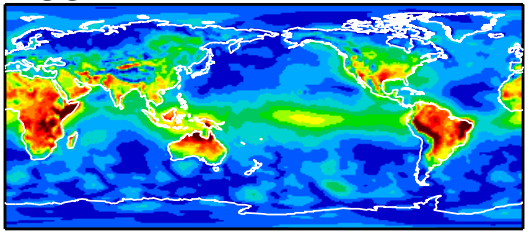

OCT

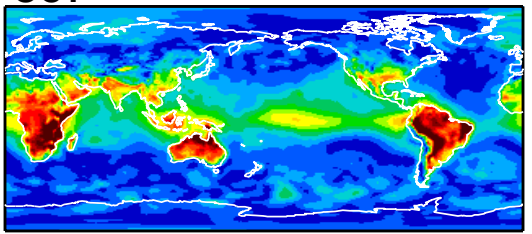

DEC

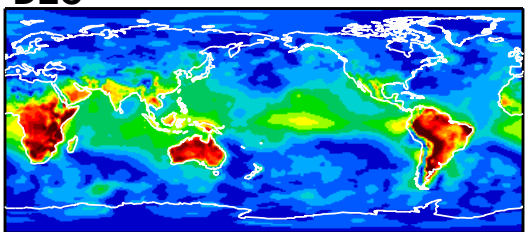

$\mu \mathrm{bar}$

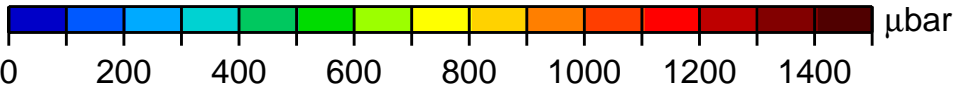

Fig. 10. Monthly mean amplitude of the $\mathrm{S}_{1}(p)$ tide as deduced from ECMWF surface pressures.

small peaks between the two tidal frequencies; close examination shows them occurring at frequencies 1.314, 1.628, 1.685 , and $1.932 \mathrm{cpd}$. The latter is the expected lunar tide $\mathrm{M}_{2}$, but the others are unexpected and correspond to no tidal or modal period that we are aware of (e.g. Hamilton and Garcia (1986) find several modal peaks in the Batavia pressure spectrum but none corresponds to Fig. 13 frequencies). The first two peaks are apparent harmonics of an $S_{1}$ modulation, since they are equidistant from $1.0 \mathrm{cpd}$. Our conjecture is that these peaks are likely spurious, related to some feature of the ECMWF processing.

Figure 14 is a "zoom" view of Fig. 13 near 1 and 2 cpd.
One sees the detailed fine structure around the tidal peaks (the fundamental spectral resolution here is $0.25 \mathrm{cpy}$ ). There is a clear, broad cusp of enhanced energy surrounding both tidal peaks. This cusp spans a frequency range of roughly $\pm 0.01 \mathrm{cpd}$ on either side of the main spectral line. In addition to the cusp, and most prominent in $S_{1}$, there are modulations of the main peaks at integral multiples of once per year. For $\mathrm{S}_{1}$ the annual modulations are relative strong, each representing about a tenth of the energy of the main line. This is consistent particularly with the oceanic regions of Fig. 12. For $\mathrm{S}_{2}$ only the semiannual modulation is apparent; if an annual modulation peak exists, it is buried within the cusp. Presum- 


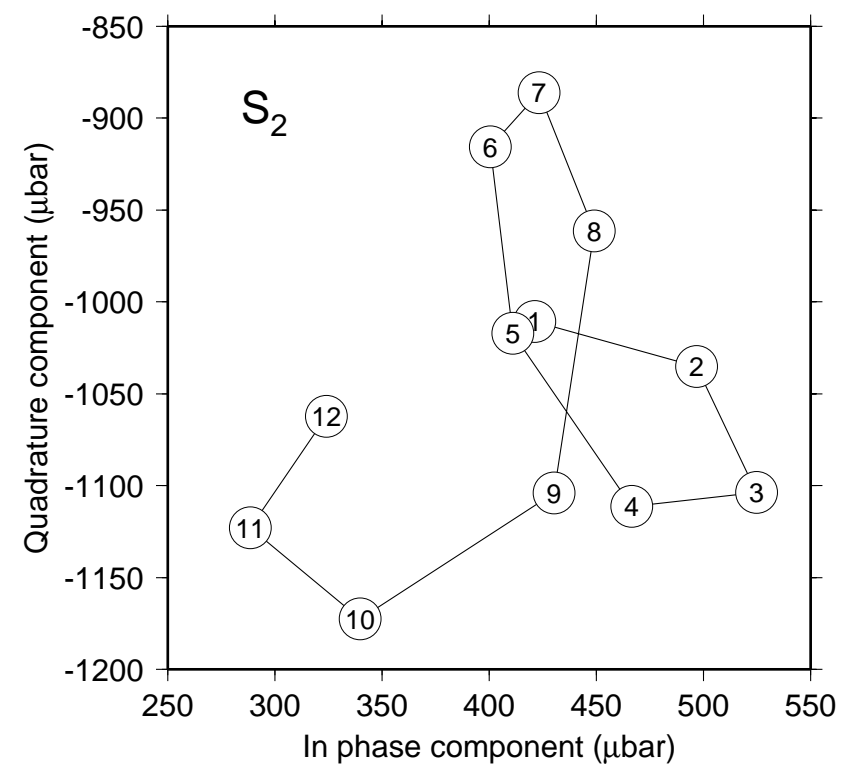

Fig. 11. Monthly estimates of the in-phase $\left(A_{2} \cos \kappa_{2}\right)$ and quadrature $\left(A_{2} \sin \kappa_{2}\right)$ components of the $\mathrm{S}_{2}(p)$ tide, averaged over all tropical regions (latitudes $\leq 23^{\circ}$ ). Months are labeled 1-12.

Table 3. Integrated energy in tidal bands, $\mathrm{Pa}^{2}$

\begin{tabular}{lcc}
\hline & $\mathrm{S}_{1}$ & $\mathrm{~S}_{2}$ \\
\hline Primary line & 1070 & 3300 \\
Secondary sideline(s) & 120 & 30 \\
Incoherent cusp & 310 & 500 \\
\hline
\end{tabular}

ably the $S_{2}$ tide has a similar structure above the Nyquist frequency, which is folded back into frequencies below $2 \mathrm{cpd}$.

Table 3 summarizes the integrated spectral densities over the appropriate frequency ranges that surround the tidal peaks of Fig. 14. In both diurnal and semidiurnal cases, the cusps represent comparable energy, about $(0.2 \mathrm{mb})^{2}$, while the modulating sidelines represent significantly smaller amounts, although more in the diurnal band than semidiurnal. In relation to the main peak, variability is more important for the diurnal tide. (Note that the values for the main peaks in Table 3 are reasonably consistent with the global $S_{2}$ and $S_{1}$ amplitude fields shown in Figs. 5 and 8, respectively: for these fields the rms over a complete tidal cycle is $570 \mu \mathrm{b}$ for $S_{2}$, corresponding to a variance of 3300 $\mathrm{Pa}^{2}$, and $315 \mu \mathrm{b}$ for $\mathrm{S}_{1}$, corresponding to a variance of 1000 $\mathrm{Pa}^{2}$.)

From Fig. 14 we conclude that the ECMWF tides display modulations at once and twice per year (and even tiny further peaks at 3,4 , and 5 times per year), but that these modulations are dominated by a complex cusp of incoherent, essentially stochastic, energy that complicates the development of simple models. For example, the monthly means of Figs. 9 and 10 could be adequately represented by an annual modulation and a few higher harmonics, but such a model would
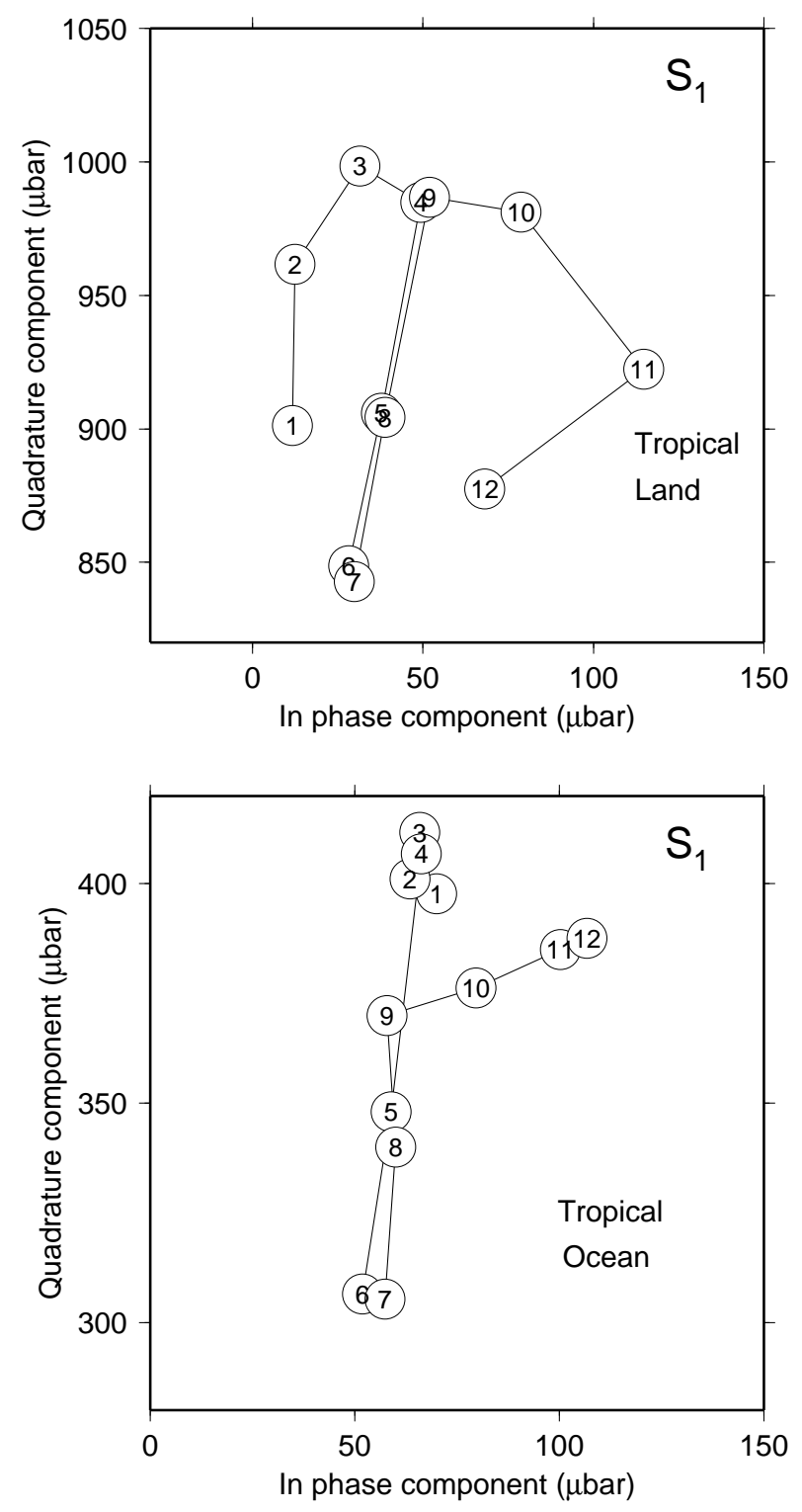

Fig. 12. As in Fig. 11 but for $S_{1}(p)$, and separated into tropical ocean and land regions.

fail to capture the majority of the tidal variability that resides within the cusps.

\section{Summary remarks}

Thirteen years of operational ECMWF fields were used to construct monthly climatologies of the daily cycle in surface pressure for the study of the $\mathrm{S}_{2}(p)$ and $\mathrm{S}_{1}(p)$ tides. Comparisons with station pressure data and products from other weather centers showed that the $S_{2}(p)$ and $S_{1}(p)$ tides are well represented in the ECMWF analysis. The available 6hourly fields sample the $S_{2}$ tide at its Nyquist frequency, but our findings indicate that simple time interpolation schemes, as proposed by Van den Dool et al. (1997) and used here, can work well in extracting the propagating $S_{2}$ tide. The ECMWF tides were found to have a phase bias of $\sim 20 \mathrm{~min}$ 


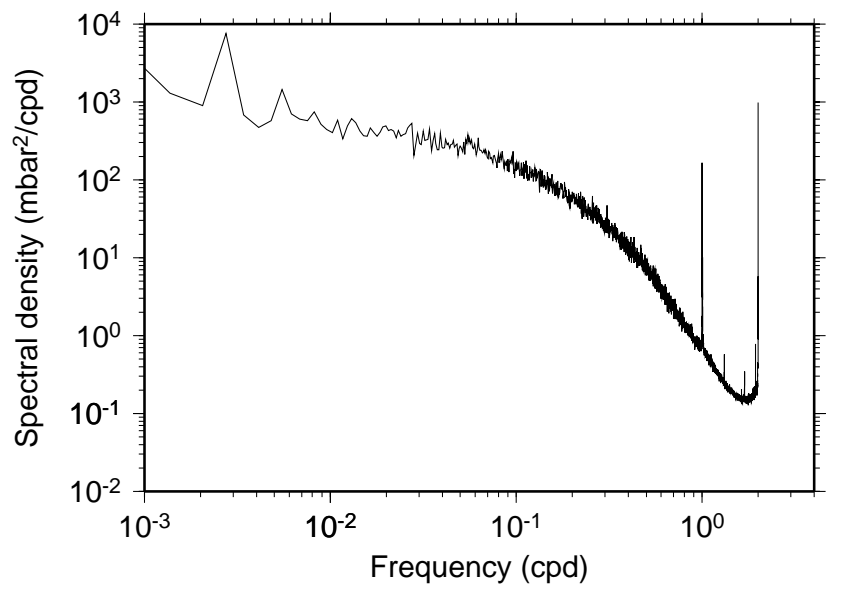

Fig. 13. Globally integrated spectrum of the ECMWF $p_{a}$ series, based on the four-year span 1996-1999. For computational details, see Wunsch and Stammer (1995).

relative to the observations. Such a shift in time can be easily corrected a posteriori, but the reasons behind it remain unclear.

Analyses of the monthly climatologies and four years (1996-1999) of 6-h fields revealed a complex, seasonal modulation of the tides superimposed on an apparently more important cusp of variability at interannual and other shorter periods. The 4-year series analyzed in Fig. 14 does not permit, however, a full evaluation of the interannual and longer period variability of the tides. Furthermore, a strong El Niño occurred in 1997-98 and may have affected the estimated tidal variability at interannual periods in Fig. 14. The study of longer records would be needed to better quantify the variability of the $S_{1}$ and $S_{2}$ tides, and, in particular, the size of the annual and semiannual modulations relative to variability at longer periods.

Acknowledgements. P. Nelson (AER) helped with initial processing of pressure fields. We thank Huug van den Dool for useful comments and discussions. Support for work at AER was provided by NASA Jason-1 Project under contract 1206432 with the Jet Propulsion Laboratory.

Topical Editor O. Boucher thanks two referees for their help in evaluating this paper.

\section{References}

Braswell, W. D. and Lindzen, R. S.: Anomalous short wave absorption and atmospheric tides, Geophys. Res. Lett., 25, 1293-1296, 1998.

Chapman, S. and Lindzen, R.: Atmospheric Tides, Gordan and Breach, New York, 1970.

Chapman, S. and Westfold, K. C.: A comparison of the annual mean solar and lunar atmospheric tides in barometric pressure as regards their worldwide distribution of amplitude and phase, J. Atmos. Terr. Phys., 8, 1-23, 1956.

Cooper, N. S.: Inferring solar UV variability from the atmospheric tide, Nature, 296, 131-132, 1982.
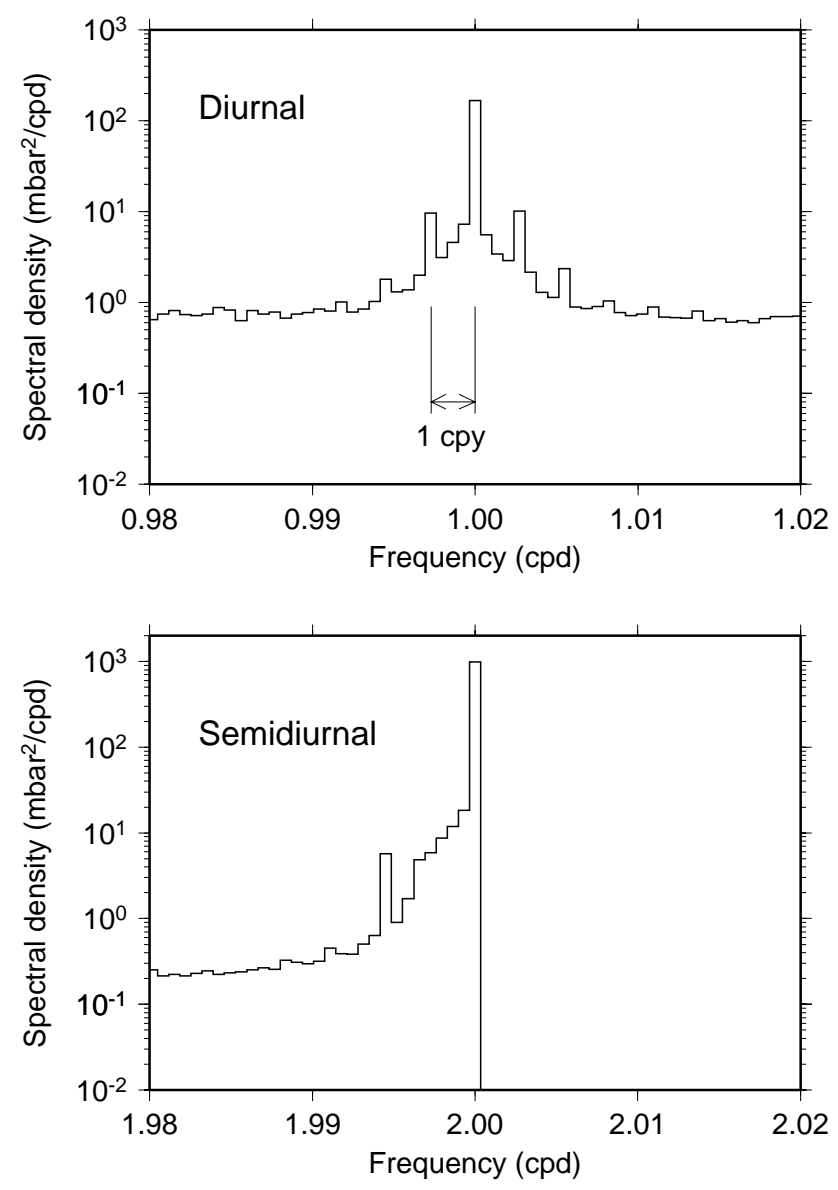

Fig. 14. Detailed views of the spectrum of Fig. 13 surrounding the diurnal and semidiurnal peaks. Frequency resolution is 0.25 cpy.

Dai, A. and Wang, J.: Diurnal and semidiurnal tides in global surface pressure data, J. Atmos. Sci., 56, 3874-3891, 1999.

Hamilton, K.: The geographical distribution of the solar semidiurnal surface pressure oscillation, J. Geophys. Res., 85, 19451949, 1980.

Hamilton, K.: Quasi-biennial and other long period variations in the solar semidiurnal barometric oscillation: observations, theory, and possible application to the problem of monitoring changes in global ozone, J. Atmos. Sci., 40, 2432-2443, 1983.

Hamilton, K. and Garcia, R. R.: Theory and observations of the short-period normal mode oscillations of the atmosphere, J. Geophys. Res., 91, 11 867-11875, 1986.

Haurwitz, B.: The geographical distribution of the solar semidiurnal pressure oscillation. New York University, College of Engineering, Meteorological Papers, 2, 5, 36 pp, 1956.

Haurwitz, B. and Cowley, A. D.: The diurnal and semidiurnal barometric oscillations, global distribution and annual variation, Pure Appl. Geophys., 102, 193-222, 1973.

Hsu, H.-H. and Hoskins, B. J.: Tidal fluctuations as seen in ECMWF data, Q. J. R. Meteorol. Soc., 115, 247-264, 1989.

Kalnay, E., Kanamitsu, M., Kistler, R., Collins, W., et al.: The NCEP/NCAR 40 year reanalysis project, Bull. Am. Met. Soc., 77, 437-471, 1996.

Lindzen, R. S.: Dynamics of Atmospheric Physics, Cambridge Univ. Press, New York, 1990. 
Madden, R. A., Lejenäs, H., and Hack, J.: Semidiurnal variations in the budget of angular momentum in a general circulation model and in the real atmosphere, J. Atmos. Sci., 55, 2561-2575, 1998.

Ponte, R. M.: Variability in a homogeneous global ocean forced by barometric pressure, Dyn. Atmos. Oceans, 18, 209-234, 1993.

Ponte, R. M. and Gaspar, P.: Regional analysis of the inverted barometer effect over the global ocean using TOPEX/ POSEIDON data and model results, J. Geophys. Res., 104, $15587-$ 15 601, 1999.

Ray, R. D.: Diurnal oscillations in atmospheric pressure at twentyfive small oceanic islands, Geophys. Res. Lett., 25, 3851-3854, 1998.

Ray, R. D.: Comparisons of global analyses and station observations of the $S_{2}$ barometric tide, J. Atmos. Solar-Terr. Phys., 63, 1085-1097, 2001.

Schubert, S. D., Rood, R. B., and Pfaendtner, J.: An assimilated data set for earth science applications, Bull. Am. Met. Soc., 74, 2331-2342, 1993.

Van den Dool, H. M., Saha, S., Schemm, J., and Huang, J.: A temporal interpolation method to obtain hourly atmospheric surface pressure tides in Reanalysis 1979-1995, J. Geophys. Res., 102,
22 013-22 024, 1997.

Velicogna, I., Wahr, J., and van den Dool, H.: Can surface pressure be used to remove atmospheric contributions from GRACE data with sufficient accuracy to recover hydrological signals? J. Geophys. Res., 106, 16415-16434, 2001.

Wahr, J., Molenaar, M., and Bryan, F.: Time variability of the Earth's gravity field: hydrological and oceanic effects and their possible detection using GRACE, J. Geophys. Res., 103, $30205-$ $30229,1998$.

Wilkes, M. V.: Oscillations of the Earth's Atmosphere, Cambridge Univ. Press, 1949.

Wunsch, C. and Stammer, D.: The global frequency-wave number spectrum of oceanic variability estimated from Topex/Poseidon altimetric measurements, J. Geophys. Res., 100, 24 895-24 910, 1995.

Wunsch, C. and Stammer, D.: Atmospheric loading and the oceanic "inverted barometer" effect, Rev. Geophys., 35, 79-107, 1997.

Zwiers, F. and Hamilton, K.: Simulation of solar tides in the Canadian Climate Centre general circulation model, J. Geophys. Res., 91, $11877-11896,1986$. 